Brit.J. vener. Dis. (1962), 38, 145.

\title{
NOTES ON THE
}

\section{BACTERIOLOGICAL DIAGNOSIS OF GONORRHOEA*}

\author{
BY
}

A. E. WILKINSON

V.D. Reference Laboratory, The London Hospital, London

In order to diagnose and control the treatment of gonorrhoea, the clinician must have access to an efficient bacteriological service. No originality is claimed for the methods described below, but they have been found to give reliable results in the routine examination of material for the gonococcus.

\section{(1) Examination of Stained Smears of Secretions for Gonococci}

Specimens of the secretion to be examined may be taken on sterile cotton wool swabs on wooden applicators or with a platinum loop. The material should be spread as thinly as possible on the slide. When swabs are used, it is preferable to transfer the material by rolling the swab along the slide rather than rotating the tip. When the material is very mucoid, better smears can be made by emulsifying it in a drop of tap water with a loop before spreading. When dry the slide is fixed by passing it rapidly through a Bunsen flame three or four times with the film of secretion uppermost. Overheating must be avoided and the slide should not be allowed to become too hot to bear on the back of the hand.

Staining must be by Gram's method; although gonococci show up very clearly with simple stains such as methylene blue, these are not sufficiently reliable for accurate diagnosis. The Gram technique described by Meyrick and Harrison (1942) is very satisfactory.

(A) 10 per cent. alcoholic crystal violet (Gurr) 1 part 1 per cent. aqueous ammonium oxalate 4 parts

Stain for one minute and rinse with water

${ }_{i}^{*}$ No. 1 of a series of invited articles.
(B) Iodine $\quad \ldots \quad \ldots \quad \ldots \quad \ldots l$ g.

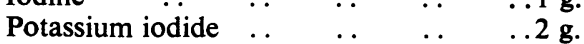
Distilled water $\quad . \quad \ldots \quad \ldots \quad 100 \mathrm{ml}$.

Flood slide and leave for one minute

(C) Rinse with water and differentiate with acetone. This takes only a few seconds, depending on the thickness of the film, and over-differentiation must be avoided.

(D) Counterstain

1 per cent. neutral red .. .. 15 parts

$90 \mathrm{ml} .5$ per cent. aqueous phenol

$9 \mathrm{ml} .10$ per cent. alcoholic basic fuchsine

1 part

Stain for one minute, rinse well, blot, and dry

Examination of Films.-Search should be made for clusters of bean-shaped Gram-negative diplococci with the longer axis of the pair lying in the plane of cleavage, situated intracellularly; a positive report should not be given unless a typical example of these can be seen. The finding of isolated pairs of Gramnegative diplococci lying outside cells should arouse suspicion but is not a sufficient basis for a firm diagnosis.

The characteristic morphology and staining reactions of the gonococcus and the fact that many are situated intracellularly makes it possible to confirm the clinical diagnosis by microscopical examination of the secretions in acute infections but this may be more difficult in chronic infections, particularly in women. Whenever there is any element of doubt, attempts must be made to culture the gonococcus, as it is only by this means that an unequivocal diagnosis can be made. 


\section{Pitfalls in the Examination of Stained Smears}

(a) Staphylococci and streptococci may occur in pairs and when phagocytosed may become Gram-variable or even frankly Gram-negative, and may superficially resemble gonococci. This is especially likely to occur when decolorization with acetone has been too prolonged. Careful examination usually shows that some of the organisms have partially retained the Gram stain, sometimes as a peripheral shell, or that one member of a pair is Gram-positive and the other Gramnegative.

(b) Short Gram-negative cocco-bacilli are frequently found in the female genital tract and are often found intracellularly. In the gonococcus the longer axis of the pair is parallel to the line of cleavage while in these cocco-bacilli it lies at right angles to the line of division between the two constituents which do not show the true flattened "coffee bean" appearance characteristic of gonococci in smears. Very tiny and very large Gram-negative cocci may be seen in material from female patients, but the size of the organisms should prevent confusion with the gonococcus; this may, however, show large swollen forms when specimens are taken shortly after treatment with penicillin. Other members of the Neisseria group may rarely be found in the genital tract, particularly in females; these are morphologically identical with gonococci and only careful cultural examination can differentiate them.

\section{(2) Cultural Diagnosis}

The simplest and most widely-used culture medium for the gonococcus is the heated blood agar ("chocolate agar") described by McLeod, Coates, Happold, Priestley, and Wheatley (1934). A convenient method of preparation is as follows:

\section{A. Meat Extract Broth Agar Base}

Fat and fibrous tissue are removed from fresh ox heart, and the muscle is minced and extracted with 1 litre tap water for each $500 \mathrm{~g}$. mince at $80-85^{\circ} \mathrm{C}$. for 3 hours. Strain liquid through muslin to remove the meat and filter it. Add 1 per cent. peptone (Oxoid) and 0.5 per cent. $\mathrm{NaCl}$ and adjust the $\mathrm{pH}$ to $7 \cdot 8$. Steam to precipitate phosphates and filter. Add 1.5 per cent. New Zealand agar, autoclave at $10 \mathrm{lb}$. pressure for $20 \mathrm{~min}$. and adjust $\mathrm{pH}$ to $7 \cdot 6$. Bottle in $225-\mathrm{ml}$. amounts and steam for $20 \mathrm{~min}$. on two successive days.

B. Melt $225 \mathrm{ml}$. agar base in the steamer and cool in a water-bath to $55^{\circ} \mathrm{C}$. Add $25 \mathrm{ml}$. sterile defibrinated horse blood previously warmed to $45^{\circ} \mathrm{C}$. Raise the temperature slowly to $75^{\circ} \mathrm{C}$. with constant gentle shaking to keep the blood uniformly suspended. Keep at $75^{\circ} \mathrm{C}$. for 5 to $10 \mathrm{mins}$. until a good chocolate colour is obtained. Pour plates. When set, incubate overnight to check sterility.

When properly made, the medium should have a uniform brown colour, exactly like a slab of milk chocolate. Plates can be stored in the refrigerator for 3 to 4 days; they should be warmed in an incubator before inoculation.

After inoculation, the plates should be incubated at $35-36^{\circ} \mathrm{C}$. in a moist atmosphere containing $\mathrm{CO}_{2}$. These conditions are most simply achieved by placing a lighted candle-end in a tin lid containing water on top of the pile of plates in a large tin with a tightlyfitting lid. After 48 hours' incubation, gonococci appear as flat, clear colonies 1 to $3 \mathrm{~mm}$. in diameter with a slightly irregular, scalloped edge; the centre may be raised and more opaque than the periphery, the colony then having the contours of a fried egg. The colonial appearance is rather variable and is influenced by the consistency and moisture content of the medium. The use of a plate microscope is most helpful in picking off colonies for subculture.

Most strains of gonococci grow well on ordinary chocolate agar, but the growth of some delicate strains can be enhanced by the addition of $5 \mathrm{ml}$. 5 per cent. Oxoid yeast extract or 5 to $10 \mathrm{ml}$. hydrocele fluid to each $100 \mathrm{ml}$. chocolate agar immediately the heating process has been completed.

A clear medium, which is more complicated to prepare, has been described by Thayer and Mahoney (1957). This gives a luxuriant growth of gonococci in primary cultures and has been found extremely satisfactory. The Nile blue incorporated in it tends to inhibit some contaminating organisms and facilitates the isolation of gonococci in pure culture from the primary plates.

\section{(3) Identification of the Gonococcus}

(a) Oxydase Reaction.-Gram-stained films are made of suspicious colonies to check the microscopic morphology, and a loopful of a freshly-prepared 0.5 per cent. solution of tetramethyl p-phenylene diamine hydrochloride is then applied to the remains of the colony. If oxydase positive, it becomes first pink and then purple within a few seconds. The oxydase reagent is toxic and subcultures must be made immediately to fresh medium. The reaction is not specific for the gonococcus but is given by other 
members of the Neisseria group, Ps. pyocyanea, Mima polymorpha (var. oxydans), some coliforms, diptheroids, micrococci, and yeasts. The reaction is often atypical with these other organisms (except the other Neisseriae and Mima), the colour not developing in the same way as with gonococci, and being sometimes restricted to the periphery of the colony. If no gonococcal colonies are seen on the plate, it is flooded with the reagent and after draining re-examined.

(b) Fermentation Reactions.-These are performed by culturing on hydrocele agar containing 1 per cent. glucose, maltose, and saccharose.

$$
\begin{aligned}
& \text { Molten sterile nutrient agar or } \\
& \text { chocolate agar base, } \mathrm{pH} 7 \cdot 6 \quad \ldots \quad 90 \mathrm{ml} \text {. } \\
& 10 \text { per cent. aqueous solution of sugar, } \\
& \text { sterilized by Seitz filtration .. } 10 \mathrm{ml} \text {. } \\
& \text { Phenol red } 0.02 \text { per cent. sterile .. } 1 \mathrm{ml} \text {. }
\end{aligned}
$$

Cool to $60^{\circ} \mathrm{C}$., add $10 \mathrm{ml}$. sterile hydrocele fluid, mix, distribute in bijou bottles, and slope. When set, incubate overnight to check sterility. A set of sugars is inoculated from an isolated colony by emulsifying the growth in the water of syneresis and spreading it over the surface of the medium. The bottles are incubated at $35-36^{\circ} \mathrm{C}$. with the caps loosened; if this is not done, sufficient $\mathrm{CO}_{2}$ may be produced to change the colour of the indicator even in the absence of fermentation of the sugar. Gonococci ferment glucose, but not maltose or saccharose; most strains will ferment glucose within $\mathbf{4 8}$ hours, but slowfermenting strains are not uncommon and may need several subcultures before they give typical reactions. Before accepting the results as valid, the purity of the growth should always be checked by examining a Gramstained film.

Although the correct reactions with the oxydase and fermentation tests are usually sufficient for the identification of the gonococcus, the ability of the organism to grow on unenriched nutrient agar at $35^{\circ} \mathrm{C}$. and at room temperature should be investigated if there is any suspicion that the strain isolated may not be a gonococcus. It should be mentioned, however, that gonococci tend to become less exacting in their nutritive requirements on prolonged subculture and may eventually grow on unenriched nutrient agar at $36^{\circ} \mathrm{C}$.; the growth in these circumstances is never so profuse as with the other saprophytic Neisseriae or with Mima polymorpha (var. oxydans), the organisms which are most likely to cause confusion.

The main difficulties in the cultural diagnosis of gonorrhoea are that the gonococcus is a fastidious organism requiring enriched media to allow it to grow. This renders it liable to be overgrown by other organisms which may be present in the inoculum, particularly in culturing secretions from the female.
Thorough cleansing of the sites from which material for culture is taken to reduce the risks of contamination and careful plating-out are of the greatest importance. Various inhibitory agents, such as crystal violet or Nile Blue A, have been incorporated in media to discourage overgrowth, but have not proved uniformly satisfactory. Crookes and Stuart (1959) have recommended the addition of 10 units $/ \mathrm{ml}$. aerosporin to the medium to inhibit overgrowth by coliforms. This is very effective against most coliform organisms but not against $B$. proteus or the other common contaminating organisms.

\section{(4) Transport Media for the Gonococcus}

Where facilities do not exist for the immediate inoculation of plates, specimens should be kept in a holding medium until they can be sent to the laboratory. A holding medium should fulfil the following requirements:

(a) Maintain the viability of the gonococcus,

(b) Prevent drying up of swabs,

(c) Discourage overgrowth of gonococci by other organisms before the specimen is finally platedout.

The transport medium described by Moffett, Young and Stuart (1948), which has been found extremely satisfactory in practice, is prepared as follows:

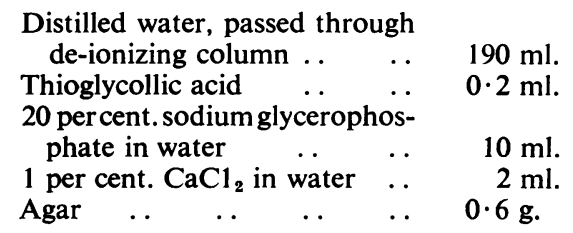

Dissolve the ingredients in the steamer and adjust the pH to 7.6 with $\mathrm{N} / 1 \mathrm{NaOH}$. Add $0.4 \mathrm{ml}$. 0.1 per cent. aqueous methylene blue and distribute in bijou bottles, filling almost to the brim. Steam for an hour and screw the caps down tightly. After cooling, keep for $24 \mathrm{hrs}$ before taking into use and reject any bottles that have become oxidized as shown by the development of a blue colour.

Swabs.-Wooden applicator sticks tipped with absorbent cotton wool are boiled in Sorensen's buffer, $\mathrm{pH} 7 \cdot 4$, dried in the oven, dipped in a 1 per cent. suspension of B.D.H. blood charcoal in water, dried, sterilized in plugged tubes in the oven. The buffer treatment is necessary, as both swabs and wool may be acid. The use of aluminium wire, instead of wooden applicators, which may be toxic, has been recommended by Beakley (1957). The charcoal neutralizes toxic substances such as fatty acids, which may be present in traces in some batches of agar. 
After the secretion has been collected on the swab, it is pushed down to the bottom of the bottle of transport medium and cut or broken off flush with the top of the bottle and the cap screwed on tightly to maintain anaerobiosis. Specimens should be kept in the refrigerator until they can be sent to the laboratory, where they should be-plated out without undue delay. Gonococci can usually be grown after storage for up to 48 hours, but after this time the frequency of isolation falls off.

Plating.-Remove the swab with sterile forceps and inoculate a previously warmed plate by rolling the swab over an area about 1 in. square. After allowing the inoculum to dry on, spread it over the plate with a loop in the usual way.

\section{(5) Determination of the Sensitivity of Gonococci to Antibiotics}

Plate Dilution Method.-Known concentrations of antibiotics are incorporated in chocolate agar plates and the series is inoculated with a uniform inoculum of the strain under investigation and a reference organism, such as the Oxford Staphylococcus, the sensitivity of which is known.

Tube-Dilution Technique.-This has been found more economical in time and materials.

MEDIUM

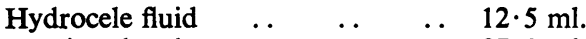

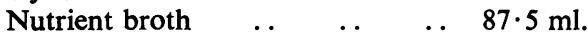

$$
\begin{aligned}
& \begin{array}{llllll}
\text { Glucose } \quad . . & . & \ldots & \ldots & 1.0 \mathrm{~g} \text {. }
\end{array} \\
& \text { Phenol red as indicator, sufficient to give a } \\
& \text { faint pink colour. }
\end{aligned}
$$

The $\mathrm{pH}$ is adjusted to $7 \cdot 4$ and the medium sterilized by Seitz filtration and distributed in 25-ml. amounts in sterile screw-capped bottles. After incubation overnight to check sterility, it is stored in the refrigerator where it will remain stable for several months. Some hydrocele fluids may be toxic to gonococci and each batch should be tested before being taken into use.

\section{Standard Solutions of Antibiotics}

Penicillin G $\quad 500$ units $/ \mathrm{ml}$. in sterile saline

Streptomycin $10,000 \mu \mathrm{g} . / \mathrm{ml}$. in sterile saline

These are stored at $-20^{\circ} \mathrm{C}$. and should be freshly prepared every 3 to 4 weeks.

A series of falling dilutions of penicillin in the sensitivity medium from 1.0 to 0.008 units $/ \mathrm{ml}$. are prepared. In the case of streptomycin, falling 4-fold dilutions from 1,000 to $1 \mathrm{\mu g} . / \mathrm{ml}$. are adequate. $0 \cdot 5-\mathrm{ml}$. amounts of the hydrocele broth + antibiotic dilutions plus a control tube without added antibiotic are transferred to a series of sterile $3 \times \frac{1}{2}$ in. tubes closed with aluminium caps.

Inoculum.-An 18 to 24-hr slope culture of the strain to be tested is washed off with broth, emulsi- fied as uniformly as possible, and diluted in broth so as to give a barely perceptible turbidity. $0.02-\mathrm{ml}$. amounts of the diluted suspension are transferred to the series of antibiotic-containing tubes and the control with a dropping pipette. Most young strains of gonococci emulsify fairly easily, although some give rather granular suspensions; the inoculum size is not critical.

Reference Organism.-One loopful of an overnight broth culture of the Oxford Staphylococcus is added to $5 \mathrm{ml}$. sterile broth and 0.02-ml. amounts are added to a further set of antibiotic dilutions. This serves as a check on the accuracy of the preparation of the antibiotic dilutions.

Reading.-The tests are incubated for $48 \mathrm{hrs}$ at $36^{\circ} \mathrm{C}$., and the end point taken as the greatest dilution in which growth is completely inhibited. A Gram-stained film or subculture should be made from the last tube showing growth to ensure the absence of contamination. Most sensitive strains of gonococci are inhibited by 0.015-0.008 units $/ \mathrm{ml}$. penicillin while the relatively insensitive strains (which are frequently isolated from patients in whom treatment with penicillin has failed) require 0.125 to 1.0 units/ ml. for complete inhibition.

Disc Sensitivity Tests. - These have not been found very helpful in assessing sensitivity to penicillin and the tube-dilution method is preferable. Streptomycin sensitivity can conveniently be checked by using sterile blotting-paper discs impregnated with $30 \mu \mathrm{g}$. streptomycin; sensitive strains show a zone of inhibition $2 \mathrm{~cm}$. or more in diameter, while resistant strains (which are usually not inhibited by as much as $1,000 \mu \mathrm{g} . / \mathrm{ml}$.) grow right up to the disc.

\section{(6) Maintenance of Stock Strains of Gonococci}

Strains can be preserved by freeze-drying, or, where facilities for this are not available, by maintenance in sloppy agar containing hydrocele fluid:

\section{NUTRIENT BRoth}

New Zealand agar .. $\quad . . \quad \ldots 0 \cdot 15$ per cent.

Hydrocele fluid $\quad . \quad \ldots \quad . .5 .00$ per cent.

Potassium chloride $\quad . . \quad \ldots 0.02$ per cent.

Calcium chloride $\quad . . \quad \ldots \quad \ldots 0.01$ per cent.

Dissolve the agar and salts in the broth, adjust to $\mathrm{pH} 7 \cdot 4$, cool to $50^{\circ} \mathrm{C}$., and add the hydrocele fluid. Tube-up in 10-ml. amounts.

The medium is inoculated at the surface with a young (18-hr) culture and is stored at $36^{\circ} \mathrm{C}$. Subcultures should be made at intervals of about 3 weeks, although some strains will maintain their viability in this medium for several months if stored in the incubator. 


\section{REFERENCES}

Beakley, J. W. (1957). Publ. Hlth Lab., 15, 11.

Crookes, E. M. L., and Stuart, R. D. (1959). J. Path. Bact., 78, 283.

McLeod, J. W., Coates, J. C., Happold, F. C., Priestley, D. P., and Wheatley, B. (1934). Ibid., 39, 221.
Meyrick, L. D., and Harrison, C. V. (1942). Ibid., 54, 517.

Moffett, M., Young, J. L., and Stuart, R. D. (1948). Brit. med.J., 2,421 .

Thayer, J. D., and Mahoney, J. F. (1957). "Gonococcus, Procedures for Isolation and Identification." U.S. Public Health Service, Education and Welfare Department. 